\title{
EFFECT OF VASOPRESSORS ON FOETAL UMBILICAL ARTERIAL BLOOD AFTER SPINAL ANAESTHESIA FOR CAESAREAN SECTION
}

Mopuru Pradeep 1 , S. Sujatha², Venugopalan Pallissery Gopalan ${ }^{3}$

${ }_{1}^{1}$ Senior Resident, Department of Anaesthesiology, Sree Gokulam Medical College and Research Foundation, Thiruvananthapuram, Kerala, India.

${ }^{2}$ Associate Professor, Department of ENT, Government Medical College, Thiruvananthapuram, Kerala, India.

3Professor, Department of Anaesthesiology, Sree Gokulam Medical College and Research Foundation, Thiruvananthapuram, Kerala, India.

\section{BACKGROUND}

ABSTRACT

Maternal hypotension produces unpleasant symptoms such as nausea, vomiting and light headedness. More importantly, when severe and sustained, hypotension can impair uterine and intervillous blood flow and ultimately result in foetal acidosis and neonatal depression. Preventive measures include fluid preload, left lateral tilt, and use of vasopressors.

Aims and Objectives-

1. To study the effectiveness of Ephedrine and Phenylephrine in the treatment of hypotension secondary to spinal anaesthesia.

2. To study the effect of vasopressors on foetal/neonatal outcome.

\section{MATERIALS AND METHODS}

In this open labelled randomised controlled trial, parturients were randomly divided into two groups. They were assigned to receive one of the two vasopressor solutions whenever maternal systolic arterial pressure (SAP) and heart rate (HR) decreased to $80 \%$ of baseline or less. SAP is measured every minute by automated oscillometry and the maternal HR by finger pulse oximetry. The sample size estimation was also done at conveniences.

\section{RESULTS}

There was no statistically significant difference between two groups in age, gender and weight of the patient and both groups were comparable. Both ephedrine and phenylephrine were effective in managing hypotension. Phenylephrine has high efficacy in increasing blood pressure. There was a decrease in $\mathrm{pH}$ in patients who received ephedrine as bolus dose for hypotension, but APGAR scores were good for all newborn infants.

\section{CONCLUSION}

Phenylephrine proves to be a better option in managing hypotension with minimal effects on foetus.

\section{KEY WORDS}

Vasopressors, Umbilical Arterial Blood, Spinal Anaesthesia, Caesarean Section.

HOW TO CITE THIS ARTICLE: Pradeep M, Sujatha S, Gopalan VP. Effect of vasopressors on foetal umbilical arterial blood after spinal anaesthesia for caesarean section. J. Evolution Med. Dent. Sci. 2018;7(49):5250-5253, DOI: 10.14260/jemds/2018/1165

\section{BACKGROUND}

Spinal anaesthesia is a common method used for caesarean delivery as it avoids the risks of general anaesthesia related to difficult intubation and aspiration of gastric contents. In spinal anaesthesia for obstetric patients, hypotension is regarded as the most common complication,(1) and estimated to occur in approximately $30 \%-90 \%$ of the patients.(2) Maternal hypotension may result in unpleasant symptoms such as nausea, vomiting and light headedness. When severe and sustained, hypotension can impair uterine and intervillous blood flow, which can ultimately result in foetal acidosis and neonatal depression.(1)

'Financial or Other Competing Interest': None.

Submission 27-10-2018, Peer Review 20-11-2018,

Acceptance 26-11-2018, Published 03-12-2018.

Corresponding Author:

S. Sujatha,

Associate Professor, Department of ENT,

Government Medical College,

Thiruvananthapuram, Kerala, India.

E-mail: drssent@gmail.com

DOI: $10.14260 /$ jemds $/ 2018 / 1165$
Stress induced catecholamine release can decrease uterine blood flow and provoke foetal asphyxia. Exogenous ephedrine and norepinephrine impairs foetal oxygenation.

When spinal anaesthesia induced hypotension and aortocaval compression co-exist, foetal acidosis is more severe.(3)

The effects on baroreceptor sensitivity have been studied, but not on their effect on maternal cardiac output or their success in maintaining maternal BP at baseline during caesarean delivery under spinal anaesthesia. However, studies over last two decade have indicated that foetal acid base status might be improved if phenylephrine or other adrenergic agonists are used during caesarean delivery instead of ephedrine. Consequently, the use of phenylephrine for arterial blood pressure management during caesarean delivery under spinal anaesthesia has been increased. The present study is done to compare the effect of vasopressors, phenylephrine and ephedrine, on foetal umbilical arterial blood after spinal anaesthesia during caesarean section. 


\section{Objectives}

1. To compare the effects of phenylephrine and ephedrine on foetal acidosis and APGAR score.

2. To compare the efficacy of both the drugs in managing hypotension, effects on heart rate and effects on nausea and vomiting.

\section{MATERIALS AND METHODS}

This is an open labelled randomised controlled trial conducted at Department of Anaesthesiology, Sree Gokulam Medical College and Research Foundation, Trivandrum. 50 patients admitted for elective caesarean section were included in the study. A sample size of 48 was obtained and divided to 25 in each group. The sample size estimation was also done at conveniences. All of them belonged to class 1 of American Society of Anaesthesiologists (ASA) classification. They were randomly allocated into two groups (Group 1 and 2) of 25 each by simple randomisation method.

Concealed cards containing numbers were given. Random number table for group 1 and 2 was taken from computer generated random number table. Accordingly allocated to two groups-

\section{Group 1}

All patients received phenylephrine as vasopressor whenever maternal systolic arterial pressure (SAP) decreased to $80 \%$ of baseline or less. They received a bolus of phenylephrine $100 \mu \mathrm{g} / \mathrm{ml}$ increments.

\section{Group 2}

These patients received ephedrine as vasopressor whenever maternal systolic arterial pressure (SAP) decreased to $80 \%$ of baseline or less. They received a bolus of $5 \mathrm{mg} / \mathrm{ml}$ of ephedrine in increments.

Duration of study was 12 months from January 2014 to December 2014.

\section{Inclusion Criteria}

1. Age more than 18 years.

2. ASA Grade 1.

\section{Exclusion Criteria}

Patients having contraindication to facial block, allergy to local anaesthetics, pre-existing systemic diseases, known foetal abnormalities, history of taking any medication that could influence hemodynamic responses and patients not willing to give consent.

All patients were fasted for 6 hours. Standard monitoring with noninvasive arterial pressure (NIBP), ECG and pulse oximetry was established. Baseline measurements were performed 5 minutes before spinal anaesthesia. 18-gauge cannula was introduced into a peripheral vein. Each patient was preloaded $15 \mathrm{ml} / \mathrm{kg}$ of ringer lactate solution. With the patient in right lateral decubitus position, lumbar puncture was performed with $2 \mathrm{ml}$ of $0.5 \%$ hyperbaric bupivacaine. Total volume of subarachnoid solution was $2 \mathrm{ml}$. After completing the intrathecal injection, patients were positioned supine on the operating table. Sensory block to T4 dermatome was considered adequate to start surgery.
Changes in maternal SAP and HR throughout anaesthesia and incidence of nausea and vomiting were recorded. SAP is measured every minute by automated oscillometry and maternal HR by finger pulse oximetry. Patients received one of the two vasopressor solutions, as per group 1 or 2 , whenever maternal SAP reduced to $80 \%$ of baseline or less. Umbilical arterial blood sample from the cord blood was obtained after delivery of the baby. Each sample was heparinised with $0.1 \mathrm{ml}$ of heparin $(1000 \mathrm{IU} / \mathrm{ml})$ and sent to ABG analysis with in 5 minutes of cord clamping. The results thus obtained were compared between the two drug groups for determination of acid base status. APGAR scores at 1 and 5 minutes of delivery for all newborn babies were noted and a score less than 8 was considered low.

Inferential statistical analysis was carried out. Results on continuous measurements were presented as mean +/- SD and that on categorical measurements in number \%. Student t test was used to find out significance of study parameters on continuous scales between two groups. Chi square test/Fisher Exact test has been used to find the significance of study parameters on categorical scales between two groups.

\section{RESULTS}

\section{Demographic Data}

\section{A) Age}

\begin{tabular}{|c|c|c|c|c||}
\hline \multicolumn{5}{|c|}{ Table 1: Age distribution of patients } \\
\hline \multirow{2}{*}{ Age in years } & \multicolumn{2}{|c|}{ Group I } & \multicolumn{2}{c|}{ Group II } \\
\cline { 2 - 5 } & No & $\%$ & No & $\%$ \\
\hline $20-24$ & 13 & 52.0 & 12 & 48.0 \\
\hline $25-29$ & 12 & 48.0 & 13 & 52.0 \\
\hline Total & 25 & 100.0 & 25 & 100.0 \\
\hline Mean \pm SD & \multicolumn{2}{|c|}{$24.28 \pm 2.65$} & $24.76 \pm 2.57$ \\
\hline \multicolumn{6}{|c|}{ Samples are age matched with $\mathrm{P}=0.519$} \\
\hline
\end{tabular}

\section{B) Weight}

Table 2: Weight $(\mathrm{kg})$ distribution in two groups of patients

\begin{tabular}{|c|c|c|c|c|}
\hline \multirow{2}{*}{ Weight (kg) } & \multicolumn{2}{|c|}{ Group I } & \multicolumn{2}{c|}{ Group II } \\
\cline { 2 - 5 } & No & $\%$ & No & $\%$ \\
\hline $60-70$ & 12 & 48.0 & 13 & 52.0 \\
\hline $71-80$ & 12 & 48.0 & 11 & 44.0 \\
\hline $81-90$ & 1 & 4.0 & 1 & 4.0 \\
\hline Total & 25 & 100.0 & 25 & 100.0 \\
\hline Mean \pm SD & $71.44 \pm 6.07$ & $69.72 \pm 5.94$ \\
\hline
\end{tabular}

\section{C) Systolic arterial pressure}

\begin{tabular}{|c|c|c|c|}
\hline SAP (mm Hg) & Group 1 & Group 11 & P value \\
\hline Baseline & $113.7+/-5.61$ & $114.4+/-6$ & 0.697 \\
\hline 1 min & $94.5+/-5.2$ & $96.6+/-5.6$ & 0.166 \\
\hline 2 min & $109+/-4.1$ & $107.4+/-3.8$ & 0.165 \\
\hline \multicolumn{4}{|c|}{ Table 3. SAP $(\mathbf{m m ~} \mathbf{H g})$} \\
\hline
\end{tabular}




\section{D) Heart Rate}

On comparison of heart rate at one minute, $12 \%$ of group 1 had a heart rate below $80 \mathrm{bpm}$ and $72 \%$ of group 1 and $84 \%$ of group 11 had heart rate between $80-95 \mathrm{bpm}$. 16\% of group 1 and 11 had heart rate greater than $95 \mathrm{bpm}$.

\section{E) Nausea and Vomiting}

\begin{tabular}{|c|c|c|}
\hline Nausea/Vomiting & Group 1 & Group 11 \\
\hline Yes & $3(12 \%)$ & $8(32 \%)$ \\
\hline No & $22(88 \%)$ & $17(68 \%)$ \\
\hline Total & $25(100 \%)$ & $25(100 \%)$ \\
\hline
\end{tabular}

$\mathrm{P}=0.08$, significant (chi square test)

\section{F) APGAR Score}

On comparison of APGAR Score at 1 minute, no babies had an APGAR Score of less than 5. 100\% of group 1 and 11 had APGAR scores of 6-8. At 5 minutes, none had an APGAR scores less than $5.28 \%$ of group 1 and 11 had APGAR scores of 6-8. 72\% of group 1 and 11 had APGAR scores of 9-10. On comparing the mean and standard deviation of APGAR score in two groups of patients at one and 5 minutes, $p$ value was above 0.05 and was not significant.

\section{G) Arterial Blood Gases}

A) $\mathbf{p H}$

\begin{tabular}{|c|c|c|}
\hline $\mathbf{p H}$ & Group 1 (n=25) & Group 11 (n=25) \\
\hline$<7.25$ & 0 & 0 \\
\hline $7.25-7.35$ & $13(52 \%)$ & $24(96 \%)$ \\
\hline$>7.35$ & $12(48 \%)$ & $1(4 \%)$ \\
\hline
\end{tabular}

$P$ value $<0.001$, Student $t$ test (Significant)

B) $\mathrm{PCO}_{2}$

\begin{tabular}{|c|c|c|}
\hline PCO $_{2}$ & Group 1 (n=25) & Group 11 (n=25) \\
\hline$<35$ & 0 & 0 \\
\hline $35-45$ & $25(100 \%)$ & $19(76 \%)$ \\
\hline$>45$ & 0 & $6(24 \%)$ \\
\hline
\end{tabular}

$P$ value $<0.001$, Student $t$ test (Significant)

C) $\mathrm{PO}_{2}$

\begin{tabular}{|c|c|c|}
\hline $\mathbf{P O}_{2}$ & Group 1 (n=25) & Group 11 (n=25) \\
\hline$<20$ & $8(32 \%)$ & $9(36 \%)$ \\
\hline $20-25$ & $16(64 \%)$ & $14(56 \%)$ \\
\hline$>25$ & $1(4 \%)$ & $2(8 \%)$ \\
\hline
\end{tabular}

$P$ value $=0.821$

\section{D) $\mathrm{HCO}_{3}$}

\begin{tabular}{|c|c|c|}
\hline $\mathrm{HCO}_{3}$ & Group 1 (n=25) & Group 11 (n=25) \\
\hline$<22$ & $6(24 \%)$ & $3(12 \%)$ \\
\hline $22-24$ & $14(56 \%)$ & $12(48 \%)$ \\
\hline$>24$ & $5(20 \%)$ & $10(40 \%)$ \\
\hline
\end{tabular}

$P$ value $=0.305$

\section{DISCUSSION}

\section{Baseline Data}

Age, gender and weight of the patient was compared between two groups. The mean age of group 1 was 24.2 and that of group 11 was 24.7. The mean weight of Group 1 was 71.4 and that of group 11 was 69.7. There was no statistically significant difference between two groups and both groups were comparable.

\section{Hypotension}

There was no consensus to the optimal mode of management in prevention and treatment of maternal hypotension due to spinal anaesthesia. In this study both ephedrine and phenylephrine were effective in managing hypotension. This was further supported by Simin. A et al(1) who found that both drugs were effective in managing hypotension after spinal anaesthesia in caesarean patients.

\section{Heart Rate Changes}

Phenylephrine has high efficacy in increasing blood pressure, but it causes reflex bradycardia leading to decrease in cardiac output. It causes more reduction in uteroplacental blood flow. On the contrary tachycardia was seen with ephedrine, because of its actions on the beta receptors of the heart.

Ngan Kee et al(4) studied the combination of phenylephrine and ephedrine in different ratios given as infusion to minimise the cardiac effects of vasopressors. They concluded that combination of vasopressors has no added advantage, compared with any vasopressor alone. This study was supported by Loughrey et al(5) in which they concluded that the combination of vasopressors was not superior to ephedrine alone.

Although phenylephrine caused bradycardia, that was not of much significance in this study as none of the patients required a supplement dose of atropine or glycopyrrolate for treating bradycardia.

\section{Dose of Drugs}

The bolus dose of phenylephrine $(100 \mu \mathrm{g})$ and ephedrine (5 $\mathrm{mg}$ ) used in this study was determined empirically. The drug dose has been taken in accordance with the study conducted by Prakash et al (6) in which they compared the efficacy of phenylephrine $(100 \mu \mathrm{g})$ and ephedrine $6 \mathrm{mg}$. Saravanon et al(7) demonstrated a potency ratio of 80:1 (Phenylephrine $(100 \mu \mathrm{g} /$ Ephedrine $(10 \mathrm{mg}))$

\section{Nausea and Vomiting}

Maternal nausea and vomiting is a significant problem during spinal anaesthesia for caesarean section. In this study, eight patients in group A (Ephedrine) and three patients in group B had nausea and vomiting. It may be due to the magnitude of hypotension and may be related to the faster response time to vasopressors. There is no significant difference between two groups.

\section{Foetal Acidosis}

There was a decrease in $\mathrm{p}^{\mathrm{H}}$ in group 11 patients who received ephedrine as bolus dose for hypotension. This may be because of reduced uteroplacental perfusion from decreased maternal artery pressure or ephedrine induced uteroplacental vasoconstriction or by a direct foetal effect of 
ephedrine. Although mild acidosis was seen in the ephedrine group, true acidosis $\left(\mathrm{p}^{\mathrm{H}}<7.2\right)$ was not seen in any of them. This may be because of the amount of drug required to treat hypotension was much lower than those used in previous studies. Utero-placental resistance or flow was not measured directly, but there is indirect evidence which suggest that reduced uteroplacental perfusion was not the main mechanism for increased incidence of acidosis in ephedrine.

Eisler et al( ${ }^{(8)}$ studied that by giving a beta 2 adrenergic stimulant to the mother for 2 hrs prior to delivery of the foetus by elective caesarean section can cause foetal metabolic academia. Ephedrine induced beta adrenergic stimulation of the foetus is a possible mechanism of foetal academic that does not involve the uteroplacental or foetoplacental circulations. This was further supported by a study conducted by Gournay et al.(9) Wright et al(10) gave ephedrine to the mother and found that it has foetal effects. It can be reflected by an increase foetal heart rate and foetal catecholamine levels.

The umbilical artery $\mathrm{PCO}_{2}$ was higher in the ephedrine group than in the phenylephrine group which may be due to increased $\mathrm{CO} 2$ production by the foetus, supporting an increase in the foetal metabolic rate in the ephedrine group.

\section{APGAR Score}

Current evidence supports APGAR Scores as a better predictor of neonatal outcome than measurement of umbilical artery $\mathrm{pH}$. Casey BM et al(11) concluded that APGAR Scoring system as a relevant predictor of neonatal survival.

In the present study, APGAR scores were good for all newborn infants, and none required tracheal intubation and ventilation, or admission to special care baby unit in the immediate post delivery period. All newborns had 5 minutes score of 8-10. There may even be benefits from foetal catecholamine stimulation before delivery. Maternal administration of a beta 2 adrenergic agonist prior to delivery by elective caesarean section can increase dynamic lung compliance, decrease airway resistance, decrease respiratory rate and reduce the risk of hypoglycaemia in the newborn infant. (8)

\section{CONCLUSION}

Phenylephrine with minimal foetal side effects proved to be a better option than ephedrine in treating hypotension in patients for caesarean section under spinal anaesthesia.

\section{REFERENCES}

[1] Simin A, Zahra F, Pouya HM, et al. Comparison of the effects of ephedrine and phenylephrine in the treatment of hypotension after spinal anasthesia during cesarean section. Open J Obstet Gynecol 2012;2(3):192-6.

[2] Erkinaro T, Kavasmaa T, Pakkila M, et al. Ephedrine and phenylephrine for the treatment of maternal hypotension in a chronic sheep model of increased placental vascular resistance. $\mathrm{Br} \mathrm{J}$ Anaesth 2006;96(2):231-7.

[3] Cooper DW, Carpenter M, Mowbray P, et al. Foetal and maternal effects of phenylepherine and ephedrine during spinal anaesthesia for caesarean delivery. Anaesthesiology 2002;97(6):1582-90.

[4] Kee NWD, Khaw KS, Ng FF. Prevention of hypotension during spinal anaesthesia for cesarean delivery: an effective technique using combination of phenylepherine infusion and crystalloid co hydration. Anaesthesiology 2005;103(4):744-50.

[5] Loughrey JPR, Yao N, Datta S, et al. Haemodynamic effects of spinal anaesthesia and simultaneous intravenous bolus of combined phenylephrine and ephedrine versus ephedrine for cesarean delivery. Int J Obstet Anesth 2005;14(1):43-7.

[6] Prakash S, Pramanik V, Chellani H, et al. Maternal and neonatal effects of bolus administration of ephedrine and phenylephrine during spinal anaesthesia for caesarean delivery: a randomised study. Int J Obstet Anesth 2010;19(1):24-30.

[7] Saravanan S, Kocarev M, Wilson RC, et al. Equivalent dose of ephedrine and phenylephrine in the prevention of post-spinal hypotension in caesarean section. Br J Anaesth 2006;96(1):95-9.

[8] Eisler G, Hjertberg R, Lagercrantz H. Randomised controlled trial of effect of terbutaline before elective caesarean section on postnatal respiration and glucose hemostasis. Arch Dis Child Foetal Neonatal Ed 1999;80(2):F88-92.

[9] Gournay VA, Roman C, Rudolph AM. Effect of beta adrenergic stimulation on oxygen metabolism in the foetal lamb. Pediatr Res 1999;45(3):432-6.

[10] Wright RG, Shnider SM, Levinson G, et al. The effect of maternal administration of ephedrine on foetal heart rate and variability. Obstet Gynecol 1981;57(6):734-8.

[11] Casey BM, McIntire DD, Leveno KJ. The continuing value of the Apgar score for the assessment of newborn infants. N Engl J Med 2001;344(7):467-71. 